Report No: ACS21198

\title{
Central Asia
}

\section{Enhancing Regional Power Trade in Central Asia}

July 2016

GEE03

EUROPE AND CENTRAL ASIA

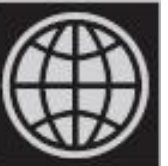




\section{Standard Disclaimer:}

This volume is a product of the staff of the International Bank for Reconstruction and Development/ The World Bank. The findings, interpretations, and conclusions expressed in this paper do not necessarily reflect the views of the Executive Directors of The World Bank or the governments they represent. The World Bank does not guarantee the accuracy of the data included in this work. The boundaries, colors, denominations, and other information shown on any map in this work do not imply any judgment on the part of The World Bank concerning the legal status of any territory or the endorsement or acceptance of such boundaries.

\section{Copyright Statement:}

The material in this publication is copyrighted. Copying and/or transmitting portions or all of this work without permission may be a violation of applicable law. The International Bank for Reconstruction and Development/ The World Bank encourages dissemination of its work and will normally grant permission to reproduce portions of the work promptly.

For permission to photocopy or reprint any part of this work, please send a request with complete information to the Copyright Clearance Center, Inc., 222 Rosewood Drive, Danvers, MA 01923, USA, telephone 978-7508400, fax 978-750-4470, http://www.copyright.com/.

All other queries on rights and licenses, including subsidiary rights, should be addressed to the Office of the Publisher, The World Bank, 1818 H Street NW, Washington, DC 20433, USA, fax 202-522-2422, e-mail pubrights@worldbank.org. 


\section{Acknowledgements}

This report was prepared under the activity "Enhancing Regional Power Trade in Central Asia" that was led by Yuriy Myroshnychenko (Senior Energy Specialist). The report produced by Kirby Owen (Consultant) draws on the findings of the technical study "Enhancing Regional Power Trade in Central Asia", carried out by AF Mercados during October 2015-June 2016. The study was based on publicly available information and energy sector data provided by Central Asian countries.

The report was prepared under the overall guidance of Ranjit Lamech (Director, Energy and Extractives Global Practice) and Sunil Kumar Khosla (Lead Energy Specialist). The team is grateful for the feedback received from the following reviewers: Husam Mohamed Beides (Lead Energy Specialist), Kari Nyman (former Lead Energy Specialist) and Debabrata Chattopadhyay (Senior Energy Specialist). The team is also thankful to Takhmina Mukhamedova (Energy Specialist), Aksulu Kushanova (Consultant), and Zamir Chargynov (Consultant) for the support provided from the World Bank offices in Central Asian countries.

The financial support by the Central Asia Energy Water Development Program (CAEWDP) is gratefully acknowledged. CAEWDP - a knowledge and technical assistance trust fund program administered by the World Bank to catalyze a renewed long-term effort to build energy and water security for the Central Asia region through enhanced cooperation; by establishing sound energy-water diagnostics and analytical tools, strengthening regional institutions, and identifying high priority infrastructure investments. CAEWDP is governed by a Donor Advisory Committee comprised of bilateral donors and multilateral institutions, representing the United States of America, the European Commission, Switzerland, the United Kingdom, and the World Bank Group. 


\section{Enhancing Regional Power Trade in Central Asia}

\section{Introduction}

In response to a request from Central Asian (CA) countries at the CAREC Energy Sector Coordination Committee meeting, held in March 2015 in Ulaanbaatar, Mongolia, the World Bank commissioned a study to estimate unrealized benefits from regional power trade for the four Central Asian countries of Kazakhstan, Kyrgyzstan, Tajikistan, and Uzbekistan ${ }^{1}$ during the period from 2010 - 2014. The study was implemented by AF Mercados from October 2015 through June 2016.

This report reviews the key findings of the AF Mercados Report, with further details to be found in the Report itself. The analysis was focused on power trade benefits aggregated at the regional level, as well as country-specific benefits. Three cases were considered, namely (i) benefits including fuel savings only at historic energy prices, (ii) benefits including both fuel savings and economic value of avoiding unserved energy at historic fuel prices, and (iii) benefits including fuel savings and the economic value of avoiding unserved energy with fuel costs estimated to be at "market" energy prices.

The findings of the report, presented in the table below, show that the benefits for the region could have amounted to nearly USD1.5 billion if only fuel savings were taken into account. Should economic value of avoiding unserved power demand be added to benefits, the benefits would have reached almost USD5.2 billion for historic energy prices and about USD6.4 billion for market energy prices. It's worth noting that each country could also have benefited in any of the cases, except for Kyrgyzstan for the case of including fuel savings only.

Table 1: Summary of Scenarios

\begin{tabular}{|l|c|c|c|}
\hline & $\begin{array}{c}\text { Benefits from fuel savings } \\
\text { only at historic energy } \\
\text { prices } \\
\text { USD million }\end{array}$ & $\begin{array}{c}\text { Benefits from fuel savings } \\
\text { and meeting unserved } \\
\text { power demand at historic } \\
\text { energy prices } \\
\text { USD million }\end{array}$ & $\begin{array}{c}\text { Benefits from fuel savings } \\
\text { and meeting unserved } \\
\text { power demand at market } \\
\text { energy prices } \\
\text { USD million }\end{array}$ \\
\hline Kazakhstan & 249 & 190 & 293 \\
\hline Uzbekistan & 608 & 3,226 & 2,932 \\
\hline Kyrgyzstan & $(68)$ & 900 & 1,813 \\
\hline Tajikistan & 699 & 879 & 1,316 \\
\hline Total & $\mathbf{1 , 4 8 8}$ & $\mathbf{5 , 1 9 5}$ & $\mathbf{6 , 3 5 4}$ \\
\hline
\end{tabular}

Furthermore, if the countries operated together, they could also save over USD 80 million annually, or USD 400 million during the period from $2010-2014$, by sharing the regional

\footnotetext{
${ }^{1}$ Turkmenistan was invited but did not participate in discussing TORs of the study and subsequently did not provide sector data. Therefore, it was not included in the study. Had it been part of the study, the estimated regional power trade benefits would have only increased.
} 
hydro resources to provide operating reserves, instead of purchasing reserves at current market prices from outside sources.

\section{The Current Situation}

\subsection{Historical Background}

The Central Asia Power System (CAPS) was designed and developed in the former Soviet Union to serve the needs of the USSR republics of Kyrgyzstan, Uzbekistan, Turkmenistan, Tajikistan and the southern portion of Kazakhstan. Both the regional transmission system (based primarily on the CAPS $500 \mathrm{kV}$ transmission "loop" transiting through Kazakhstan, Uzbekistan and Kyrgyzstan) and overall operating regimes were developed in order to allow the coordinated and optimized use of fossil fuel and hydroelectric resources throughout the region to meet electrical demand while at the same time managing water flows for irrigation purposes.

Following the dissolution of the Soviet Union in 1991, the five newly independent republics initially acted to put in place a framework of intergovernmental agreements intended broadly to maintain many of the operating goals of the previously integrated system. An agreement on parallel electricity system operations was signed in late 1991, and an agreement on water sharing (essentially maintaining previous Soviet practices) was signed in early 1992.

However, soon after obtaining independence in 1991, differences both in domestic interests and priorities as well as in natural resource endowments among the independent republics put pressure on these and subsequent related agreements. Problems adhering to agreed energy import / export levels as well as water release volumes appeared, and became particularly apparent in years of extreme hydrology.

Over time, the operations of CAPS evolved. In 2003, Turkmenistan effectively withdrew (apart from occasional bilateral transactions) and synchronized with the Iranian system. In 2009, a series of changes left Tajikistan essentially isolated from CAPS, with only some lower voltage level connections with Kyrgyzstan available.

It should be noted that throughout this historical period (as well as at present), the energy situation within CAPS, especially in the hydropower-based systems of Tajikistan and Kyrgyzstan, has been one marked by both seasonal (winter) energy shortages and (summer) surpluses, together with a strong joint reliance on the trans-boundary transmission interconnections. Prior to the problems experienced in 2009 , the ability to use the region's hydro resources nearly optimally helped to alleviate the problem of summer surpluses, and, via trade or energy exchange (barter), somewhat mitigate winter shortages. Nevertheless, shortages still occurred, and today with a smaller CAPS (and increasing load growth) the problem has become more acute, even in countries with dominant thermal generation. 


\subsection{The Current Situation}

The current situation in CAPS can be characterized as one of steady load growth, coupled with high and increasing levels of energy-not-served (ENS, or "unserved energy") in some countries, and economically inefficient use of regional energy resources. These characteristics, taken together, contribute to a costly situation for the region.

Figures 1 and 2 below show the pattern of actual electricity consumption and overall estimated demand for the region and also each of the four countries during the $2010-2014$ period.

Figure 1: Regional Consumption and Demand (Consumption+ENS) $(2010-2014$ total GWh 000)

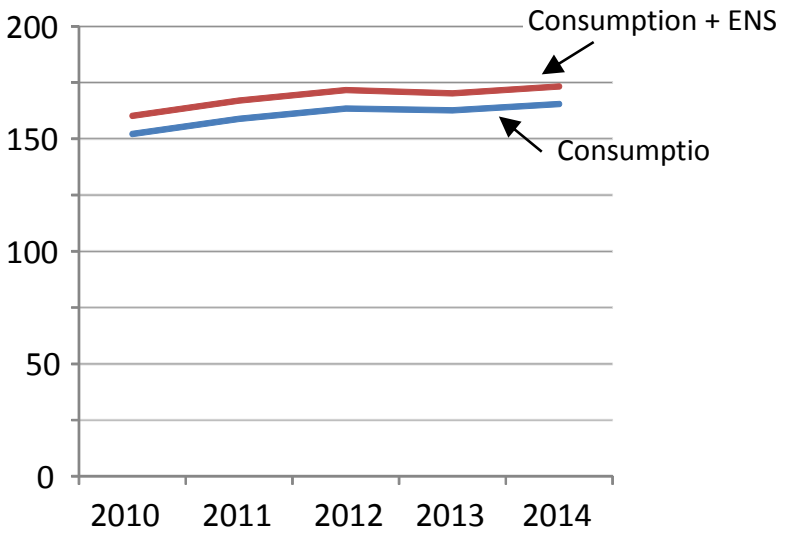

Figure 2: Average Demand Growth Rate By Country, 2010 -- 2014

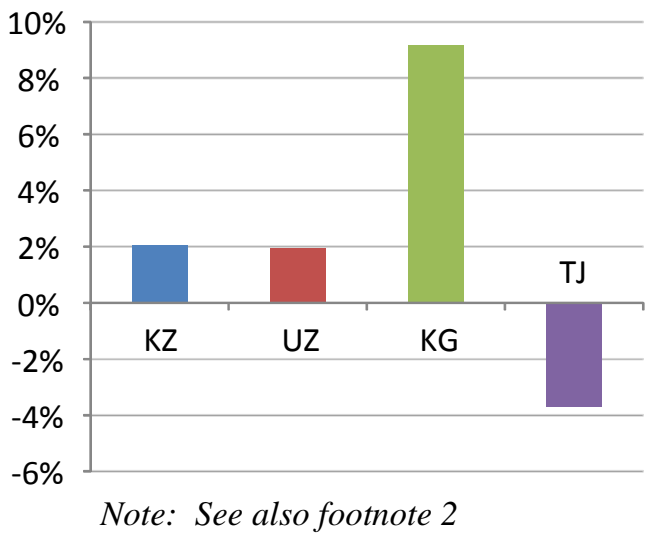

As Figure 1 shows, demand ${ }^{2}$ growth for the region as a whole was generally steady, averaging about $2 \%$ per annum throughout the period. Unserved energy was typically about $5 \%$ of total consumption in each year, and limited to Uzbekistan, Kyrgyzstan, and Tajikistan.

Figure 2 shows that despite the fairly steady regional growth, there were significant differences among the countries.

The fact that regional resources are used inefficiently is probably best illustrated by the pattern of water spillage from hydroelectric plants over the period. Figure 3 shows the energy lost by water spills in each year of the period:

\footnotetext{
${ }^{2}$ By "demand", we refer to actual consumption plus the estimated unserved energy (i.e., shortages and customer curtailments). Note that Tajikistan's consumption (and demand) fell over the period (as shown in Figure 2) primarily due to the reduction in production at the aluminium smelter TALCO. In years prior to the study period, TALCO represented as much as $40 \%$ of Tajik consumption; by the end of the study period it had dropped to $26 \%$.
} 
Figure 3: Water Spills by Country, GWh

$2010--2014$

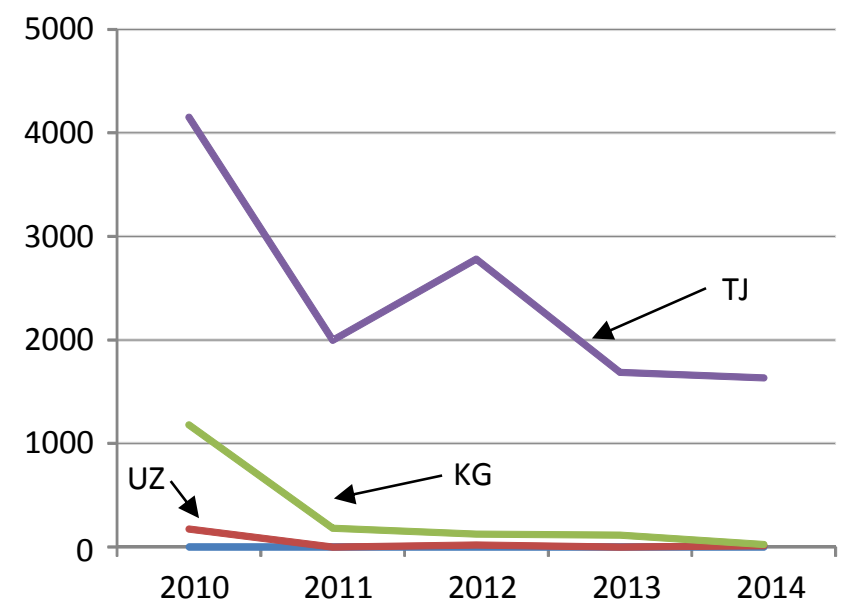

The most significant energy losses due to water spills occurred in Tajikistan, which could be expected due to its currently limited transmission links in the region. Spills also occurred in Kyrgyzstan and (to a lesser extent) Uzbekistan. Only Kazakhstan had no reported energy losses due to water spills.

In total, the energy lost due to water spills varied from about $1 \%$ to $3.6 \%$ of aggregate regional energy consumption annually. While this may seem like a small proportion, the analysis of the Report shows that harnessing these losses through better interconnection and efficient trade has significant economic value.

Finally, the overall level of cross-border trade throughout the region is itself an indicator of the general failure to efficiently utilize and share regional resources. Over the period from $2010-2014$, the average annual power flows among the countries of the region were only about $10 \%$ of the level achieved in the early 1990s. This is a stark indicator of the evergrowing inefficiency of trade in the region.

\section{The Analysis}

\subsection{Objectives of the Analysis}

There have been previous studies ${ }^{3}$ of the potential benefits of efficient energy trade in the region. While these studies have always shown benefits, they have tended to focus on these benefits within the context of a forward-looking analysis, often focused also on system development issues.

This study has instead been structured to look backwards at what happened historically during a specific period (i.e., for the years 2010 - 2014), and then to calculate what incremental economic benefits would have been obtained had efficient trade been pursued

\footnotetext{
${ }^{3}$ See, for example, "Central Asia Regional Economic Cooperation: Power Sector Regional Master Plan", October 2012, prepared by Fichtner GmbH \& Co. for the Asian Development Bank, and "Load Dispatch and System Operation Study for Central Asian Power System", October 2010, prepared by Mercados Energy Markets International (Spain) for the World Bank.
} 
throughout that period. Specifically, the analysis was focused on the following three questions:

- What would have been the aggregate additional benefits for the four-country region had efficient trade been pursued?

- How might those total benefits been distributed among the four countries had a set of pricing rules which evenly shared the benefits for cross-border trade been adopted?

- How might those benefits have changed if fuel prices for generation in the region had been at "export market" levels for cross-border trade, rather than at the levels which historically prevailed?

The "backward-looking" focus for the analysis was chosen specifically in order to eliminate uncertainty over the sorts of assumptions which need to be made in forward-looking analyses (e.g., assumptions regarding future demand levels, fuel prices, availability and cost of new capacities, etc). However, as we have noted above, previous "forward-looking" studies have been performed and the general message - that efficient trading brings substantial regional benefits - is consistent throughout all of these analyses.

\subsection{Structure of the Analysis}

The analysis is based on a set of simulations of four-country operations (i.e., dispatch) for the historical period 2010 - 2014. Each simulation is based on differing assumptions, thus creating individual different scenarios. Table 2 below summarizes the characteristics of each of the individual simulation scenarios, with further descriptions following the Table.

\section{Table 2: Summary of Scenarios}

\begin{tabular}{|c|c|}
\hline Scenario & Characteristics \\
\hline $\begin{array}{l}\text { REAL SIM C } \\
\text { ENS }\end{array}$ & $\begin{array}{l}\text { - Dispatch based on historic values of generation, consumption, fuel prices } \\
\text { and approximated historic levels of cross-border power exchange (though } \\
\text { Tajikistan is modelled as completely isolated). }\end{array}$ \\
\hline T100C ENS & $\begin{array}{l}\text { - Economic least-cost dispatch, with } 100 \% \text { of cross-border transmission } \\
\text { capacity available } \\
\text { - Historic levels of consumption and fuel prices }\end{array}$ \\
\hline REAL SIM C & $\begin{array}{l}\mathrm{h} \text { based on historic values of generation, consumption, fuel prices } \\
\text { roximated historic levels of cross-border power exchange (though } \\
\text { an is modelled as completely isolated). }\end{array}$ \\
\hline T100C & $\begin{array}{l}\text { - Economic least-cost dispatch, with } 100 \% \text { of cross-border transmission } \\
\text { capacity available } \\
\text { - Historic levels of demand (i.e., actual consumption plus estimated actual } \\
\text { unserved energy) and fuel prices }\end{array}$ \\
\hline REAL SIM & $\begin{array}{l}\text { - Dispatch based on historic values of generation, consumption, and } \\
\text { approximated historic levels of cross-border power exchange (though } \\
\text { Tajikistan is modelled as completely isolated). } \\
\text { - Fuel costs (for the computation of import / export benefits) correspond to } \\
\text { "export" price levels with USD } 20 \text { / ton cost for } \mathrm{CO}_{2} \text { emissions }\end{array}$ \\
\hline T100 & $\begin{array}{l}\text { - Economic least-cost dispatch, with } 100 \% \text { of transmission capacity } \\
\text { available } \\
\text { - Historic levels of demand } \\
\text { - Cross-border electricity trade and dispatch based on "export" fuel prices }\end{array}$ \\
\hline
\end{tabular}




\begin{tabular}{|l|l|}
\hline & \multicolumn{1}{|c|}{ with USD 20 / ton cost for $\mathrm{CO}_{2}$ emissions } \\
\hline T033 & $\begin{array}{l}\text { Economic least-cost dispatch, with } 33 \% \text { of cross-border transmission } \\
\text { capacity available }\end{array}$ \\
& $\begin{array}{l}\text { - Historic levels of demand } \\
\text { Cross-border electricity trade and dispatch based on "export" fuel prices } \\
\text { with USD 20 / ton cost for } \mathrm{CO}_{2} \text { emissions }\end{array}$ \\
\hline T066 & $\begin{array}{l}\text { Economic least-cost dispatch, with } 66 \% \text { of cross-border transmission } \\
\text { capacity available }\end{array}$ \\
& $\begin{array}{l}\text { Historic levels of demand } \\
\text { Cross-border electricity trade and dispatch based on "export" fuel prices } \\
\text { with USD 20 / ton cost for } \mathrm{CO}_{2} \text { emissions }\end{array}$ \\
\hline
\end{tabular}

The first two pairs of scenarios - REAL SIM C andT100C ENS, followed by REAL SIM C and $\mathrm{T} 100 \mathrm{C}$, all shaded in the table above - are the principal scenarios of focus for this work.

- The "REAL SIM C ENS" scenario can be considered as the "Base Case" for the analysis of estimating "cash costs" benefits. It is structured to simulate (within the bounds of the modelling tools and techniques) the actual total cost of operating the four-country system as it was actually operated (in terms of generation, hydro utilization, cross border power flows, levels of consumption and unserved energy, etc.) during the five-year period. It was developed based on data from CDC Energia.

- The "T100C ENS" scenario is the main "Efficient Trade" scenario. It is structured to retain the same levels of generation and hydro utilization availability, but to dispatch the system not as it actually was dispatched, but instead in an aggregate four-country least-cost basis in order to serve power demand observed in the REAL SIM C scenario. In addition, the T100C scenario makes the full transmission capacity of the modelled system (see explanation below) available for cross-border trade, including restoration of the Tajik system to the CAPS grid.

- The "REAL SIM C" case is similar to the REAL SIM C ENS case, but structured to track ENS levels in order to allow estimation of the benefits of serving unserved energy (in the T100C case). It differs from the REAL SIM C ENS case only due to small modelling effects.

- The "T100C" scenario is the same as the T100C ENS scenario, except for meeting total demand (i.e., actual consumption, as observed in the REAL SIM $\mathrm{C}$ scenario, plus estimated unserved energy) as well as possible.

- $\quad$ The T100 scenario mirrors the assumptions of the T100C scenario, but instead uses "export market" prices for fossil fuels, including a charge for $\mathrm{CO}_{2}$ emissions to optimize aggregate system dispatch and to assign values to crossborder trade. This scenario was designed to help answer the question of how the benefits of trade might have been affected had fossil fuel-based energy been priced at "market" levels for export/import substitution as electricity or as exports as fuel during the period. In the analytical results, it is paired with a "REAL SIM" alternative base case which itself is also based on the same assumptions regarding fuel prices and carbon costs. 
- The "T033" and "T066" scenarios are conceptually the same as the T100 scenario, with the exception that cross border transmission capacities are limited to $33 \%$ and $66 \%$ respectively of actual total capacity

The system simulation modelling was carried out using the "SDDP" model which is able to dispatch the combined thermal / hydro system taking into account major transmission links. The four-country system was modelled as individual countries connected by transmission links, with two countries (Kazakhstan and Tajikistan) further incorporating internal north / south transmission limitations. The general schematic of the physical system modelled is shown in Figure 4 below.

Figure 4: SDDP Regions and Maximum Transfer Capacity (MW)

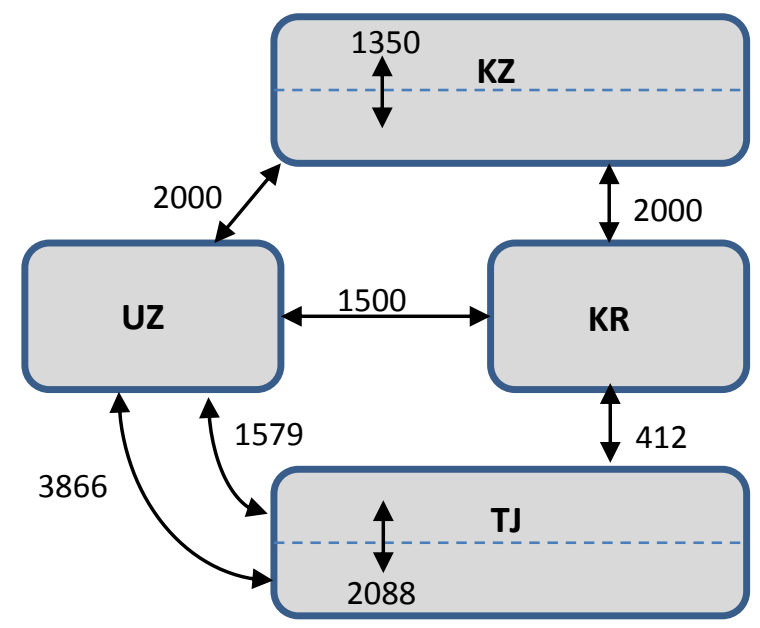

Further details of the SDDP model, the modelling methodology, and various input data can be found in Chapter 4 of the AF Mercados Report.

The analysis proceeded by computing the full four-country system operating cost corresponding to each case and using the differences in this total costs between cases to determine the incremental benefits of efficient trade (represented by the economic least-cost dispatch) in any individual case relative to the appropriate Base Case (e.g., by comparing the T100C case to the REAL SIM C case). The operating costs were represented by variable operating costs (fuel plus variable O\&M costs) of generation, plus an additional economic cost of USD 150 / MWh for any unserved energy in the scenario ${ }^{4}$.

Thus, if a scenario (e.g., T100C) was able to use system resources more efficiently than the Base Case scenario, either by using overall resources to reduce the base case levels of unserved energy and / or to use cheaper (hydro) resources to reduce the use of more expensive fossil fuels, then that scenario would show aggregate benefits relative to the Base Case. The analysis further was able to estimate a reasonable allocation of those benefits on a country-by-country basis by creating an artificial "price" for cross-border power exchanges where the "price" was based on the marginal cost of the power exchange. While it is recognized that this latter analysis relies on a "modelled" or artificial pricing rule, the

\footnotetext{
${ }^{4}$ AF Mercados have also performed a sensitivity analysis which essentially does not assign a benefit to meeting historically unserved through trade, and limiting economic benefits essentially to fuel savings. This sensitivity analysis is described in Section 4.2 below.
} 
analysis itself is intended to demonstrate whether it is possible that with a reasonable pricing scheme, benefits might flow to all countries. As the analysis described in the next section shows, in fact this is the case.

Finally, a separate calculation was also made to estimate the total savings to the region of maintaining reserve requirements since a more fully integrated four-country system would be expected to need to maintain fewer reserves than a more independent country-by-country operation.

\section{Results: Fuel Savings only from Efficient Trade at Historic Fuel Prices (REAL SIM C ENS vs T100C ENS)}

In this analysis, the objective was to estimate the benefits of efficient trade (with historic fuel prices) while meeting historic consumption levels in each of the countries. It is important to note that "historic consumption levels" are different from "historic demand levels" because the latter includes unserved energy (as was shown in Figure 1). While the economic benefit of avoiding unserved energy is certainly real, it is not a direct and immediate "cash expense", and so this analysis can be viewed as determining the cash-only benefits of implementing efficient trade with historic fuel prices.

\subsection{The Base Case: REAL SIM C ENS}

In the REAL SIM C ENS case, the system was operated on the basis of historical actual generation, with cross border flows constrained (within model capabilities) to actual levels. Figure 5 below shows the aggregate 5-year system dispatch by fuel type, and Figure 6 shows the total generation by each individual country.

Figure 5: REAL SIM C ENS Case Aggregate Despatch (2010 - 2014 total GWh 000)

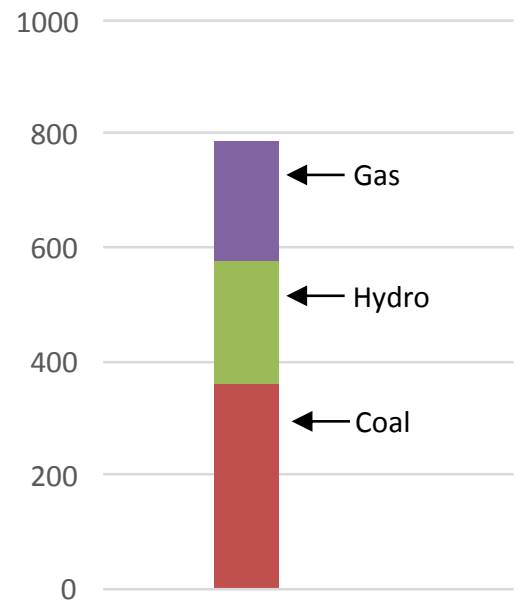

Figure 6: REAL SIM C ENS Despatch by Country (2010 - 2014 total GWh 000)

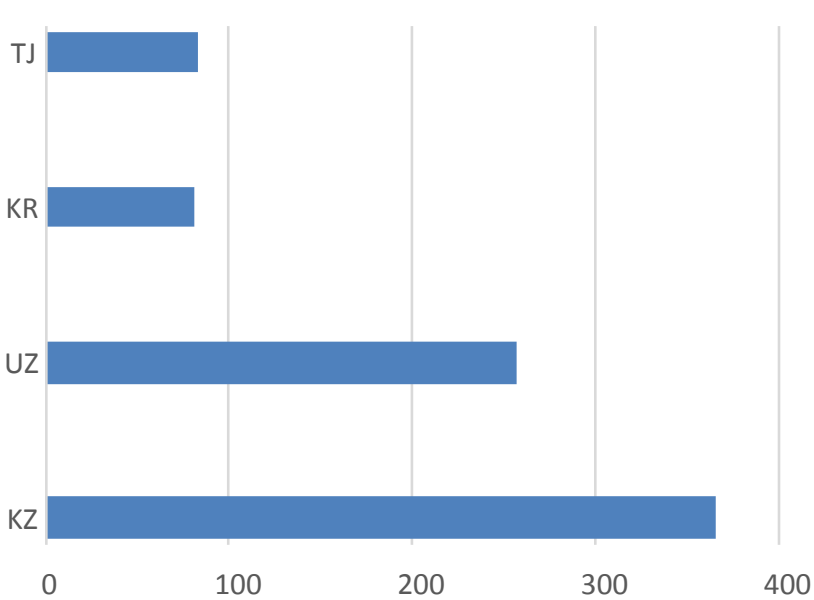

The system is dominated by coal-fired production, with a roughly even split between gas and hydro for the remainder (recognizing that in this base case there are still substantial hydro spills due to lack of trade).

As a benchmark for later comparisons, we note that the calculated level of $\mathrm{CO}_{2}$ emissions for the five-year period covered in this scenario are approximately 500 million tons in aggregate. The system's cross border flows (as modelled) are shown in Figure 7 below. 


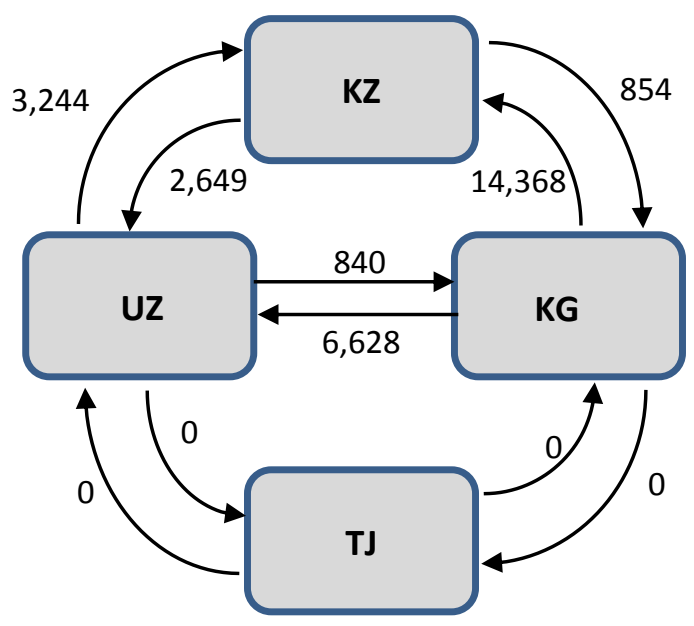

\subsection{Efficient Trade, Fuel Savings Only: T100C ENS}

The efficient trade case for assessing the value of fuel savings (ignoring unserved energy) uses the same level of fuel costs and consumption as the REAL SIM C ENS case, but removes constraints on individual station generation levels and actual transmission capacity usage. By removing these restrictions, the system can be dispatched to meet consumption levels on a least-cost basis, subject only to actual physical maximum transmission constraints. Furthermore, it is also assumed that Tajikistan is physically re-connected to CAPS, thus restoring the effective transmission links shown in Figure 5 above.

Figures 8 and90 below illustrate the system-wide dispatch results of the T100C ENS case relative to the REAL SIM C ENS Base Case (which has also already been shown previously in Figures 5 and 6).

Figure 8: Aggregate Despatch (2010 - 2014 total GWh 000)

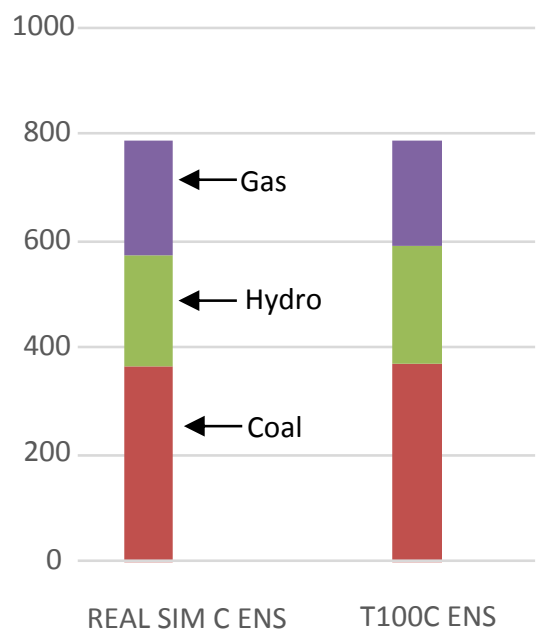

Figure 9: Despatch by Country (2010 - 2014 total GWh 000)

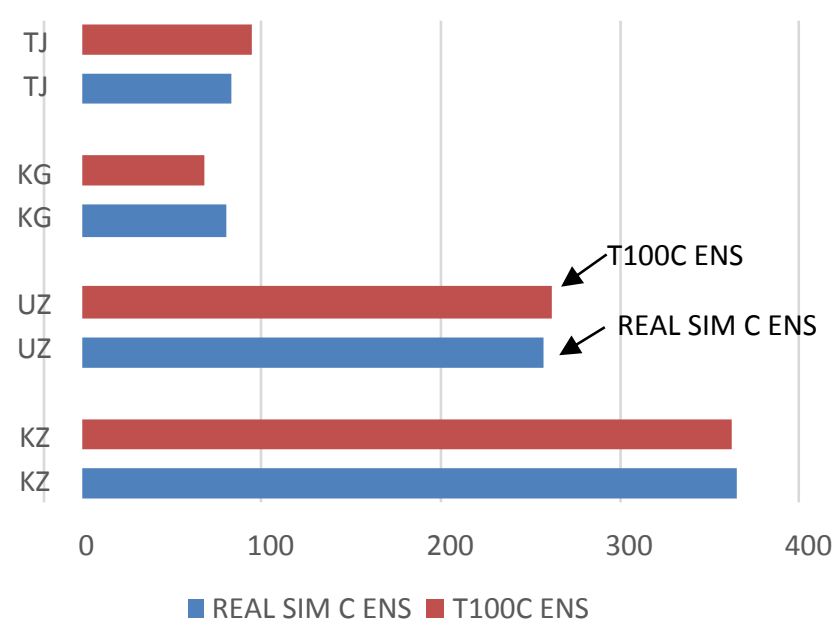


It is worth noting the (expected) increase in hydro generation (due to lack of water spills) with the corresponding reduction mostly in high-cost gas-fired generation.

The total $\mathrm{CO} 2$ emissions over the five-year period for this scenario are actually less than in the Base Case, corresponding to 492.6 million tons, or about a $1.5 \%$ reduction in emission levels. This is due primarily to the substitution of hydro energy for gas-fired generation.

Figure 10 below illustrates the cross border power flows of T100 C ENS, with Figure 11 showing the incremental flows (with decreases in parentheses) of the T100 C ENS case relative to the REAL SIM C case.
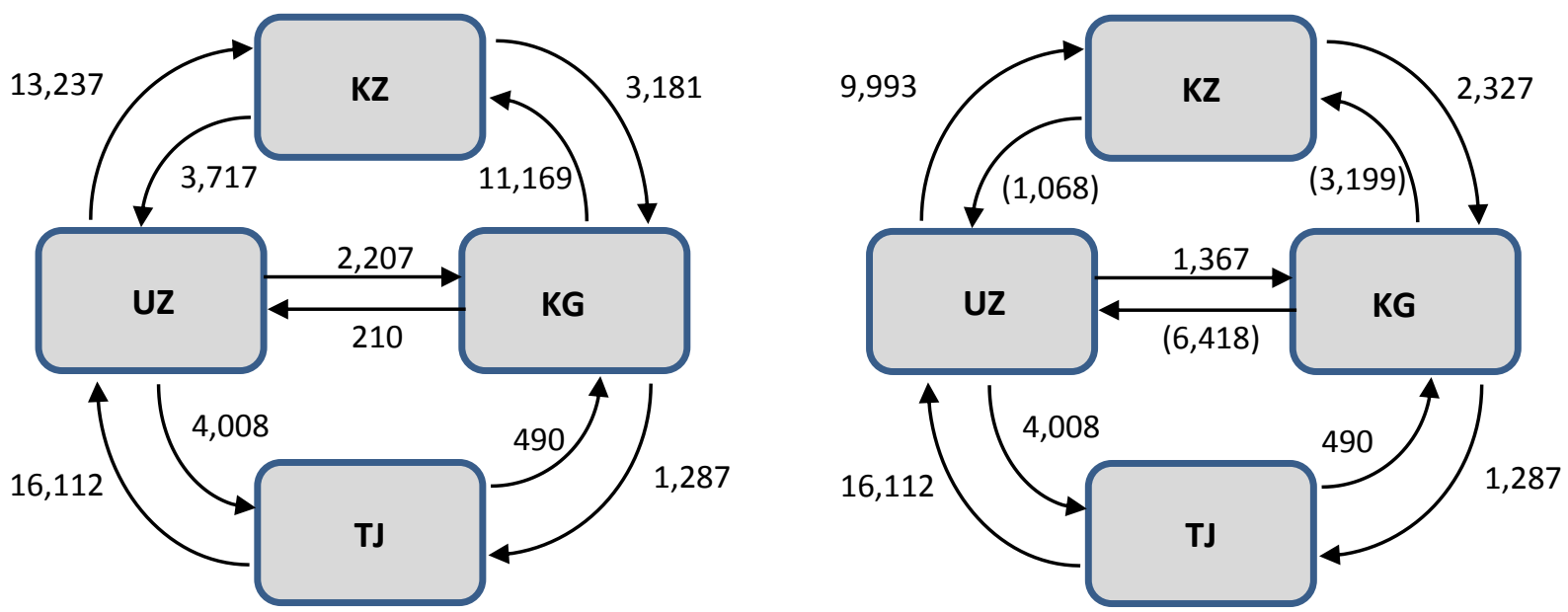

The incremental benefits (cost savings) and incremental costs for the T100C ENS case relative to the REAL SIM C case are shown in Figure 12 below.

Figure 12: Benefits of Efficient Trade, Excluding Value of Avoiding Unserved Energy (T100C ENS vs REAL SIMC ENS) (2010 - 2014 total USD Billions)

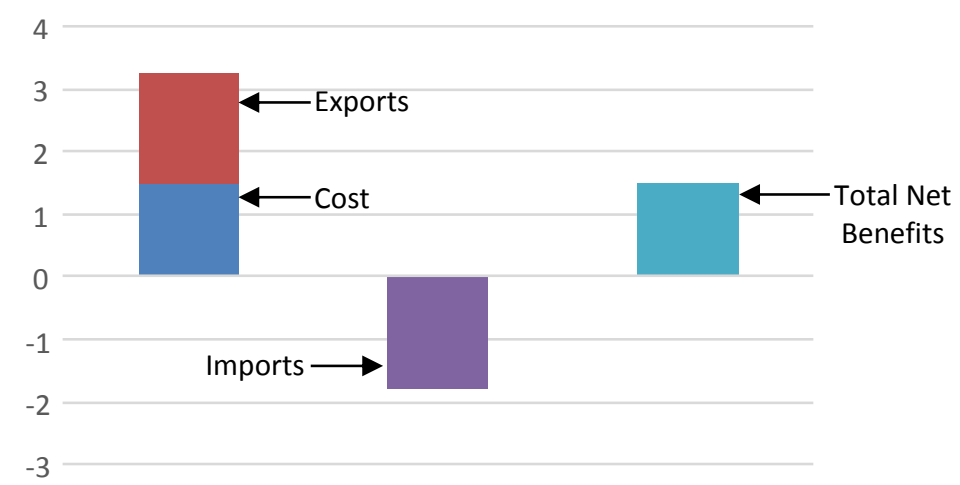

The figure shows the various incremental costs and benefits by component. These components include: 
- Cost: This represents the dispatch cost (fuel and variable O\&M) of operating the system. In this Figure, it can be seen that cost is shown as an incremental benefit (i.e., a positive value in the figure), thus telling us that the system operating cost actually decreased (due to better utilization of hydro resources) in the Efficient Trade scenario relative to the Base Case.

- Unserved Energy: This is not shown in the above figure since the quantity of unserved energy was intentionally held constant in the two cases. However, in the results for other scenarios (described in Sections 4 and 5 below), the efficient trade cases will reduce unserved energy, thus providing an economic benefit. The value of this economic benefit (calculated at USD $150 / \mathrm{MWh}$ ) will in these subsequent cases be shown as a positive benefit in the appropriate later figures.

- Imports and Exports: Within the region, there are substantially more crossborder trades (i.e., imports and exports) in the Efficient Trade case relative to the Base Case. These trades are "priced" based on the marginal costs of production in individual hours modelled. The bars for "exports" and "imports" simply represent the price multiplied by the quantity of the power flow. In the aggregate analysis, the total costs of imports should balance the total costs of exports, although they will of course vary country-by-country. However, the increased power flows also cause increased transmission losses which are accounted for in the "import" value 5 . It is useful to note that from an economic perspective, the "economic value" of an export or import will be the total money paid for the power exported or imported (which is what is shown in these bars), net of the change in dispatch costs for either country (which is accounted for in "cost" above) or, for the importing country, reductions in unserved energy (also noted above).

- Net Benefits: The net benefits are simply the sum of the individual positive benefits (in this instance, "exports" and "cost") less the increased costs (in this instance, "imports"). The aggregate regional net benefits here come to approximately USD 1.5 billion over the five-year period.

\subsection{Individual Country Benefits}

It is useful also to consider the distribution of these total benefits among the four countries. Table 3 below summarizes the country-by-country situation.

\footnotetext{
${ }^{5}$ In addition, there are also (small) effects related to how assumed costs in the (later-described in Section 4) T100 scenario might affect the economics of extra-regional imports / exports.
} 
Table 3: Economic Benefits of Efficient Trade, Holding Constant Unserved Energy (T100C ENS vs REAL SIMC ENS)

(2010 - 2014 total USD Millions)

\begin{tabular}{|l|c|c|c|c|c|}
\hline Country & $\begin{array}{c}\text { Dispatch } \\
\text { Cost }\end{array}$ & Imports & Exports & $\begin{array}{c}\text { Unserved } \\
\text { Energy }\end{array}$ & Total \\
\hline Kazakhstan & 553 & $(542)$ & 239 & -- & 249 \\
\hline Uzbekistan & 259 & $(640)$ & 989 & -- & 608 \\
\hline Kyrgyzstan & 595 & $(276)$ & $(387)$ & -- & $(68)$ \\
\hline Tajikistan & 67 & $(326)$ & 958 & -- & 699 \\
\hline Total & 1,474 & $(1,784)$ & 1,798 & -- & 1,488 \\
\hline
\end{tabular}

It can be seen that all countries (apart from hydro-dominated Tajikistan) enjoyed substantial Dispatch Cost savings as previously-spilled or under-utilized hydro resources in the region were applied to reducing fossil fuel costs. All countries enjoyed substantial benefits, apart from Kyrgyzstan. For Kyrgyzstan, while the country enjoyed the greatest fossil fuel cost savings, it also lost value on its export sales (due to more hydro-electricity generally reducing cross-border prices throughout the region) and of course purchased imports in order to reduce its fossil fuel costs. These competing factors almost exactly balanced out its dispatch cost savings, leaving Kyrgyzstan with a small negative benefit over the 5-year period. The other countries had total benefits ranging from about a quarter to over half a billion USD.

\section{Results: Benefits from Fuel Savings and Meeting Unserved Power Demand via Efficient Trade (REAL SIM C vs T100C)}

In this section, we analyze the economic benefits of efficient trade including the value of meeting previously unserved energy demand as well as dispatch fuel savings. This is achieved through the creation of a new base case ("REAL SIM C" which is quite similar to REAL SIM C ENS and differs primarily due to modelling details) and a new efficient trade case ("T100C") which both optimizes dispatch and trade (using full transmission capability) and attempts to meet total demand rather than merely historic consumption levels.

\subsection{The Base Case: REAL SIM C}

In the REAL SIM C case, the system was operated on the basis of historical actual generation, with cross-border power flows constrained to actual levels. Figure 13 below shows the aggregate 5-year system dispatch (by fuel type) and aggregate system unserved energy, while Figure 14 shows the total generation by each individual country. 
Figure 13: REAL SIM C Case Aggregate Despatch and Unserved Energy $(2010$ - 2014 total GWh 000)

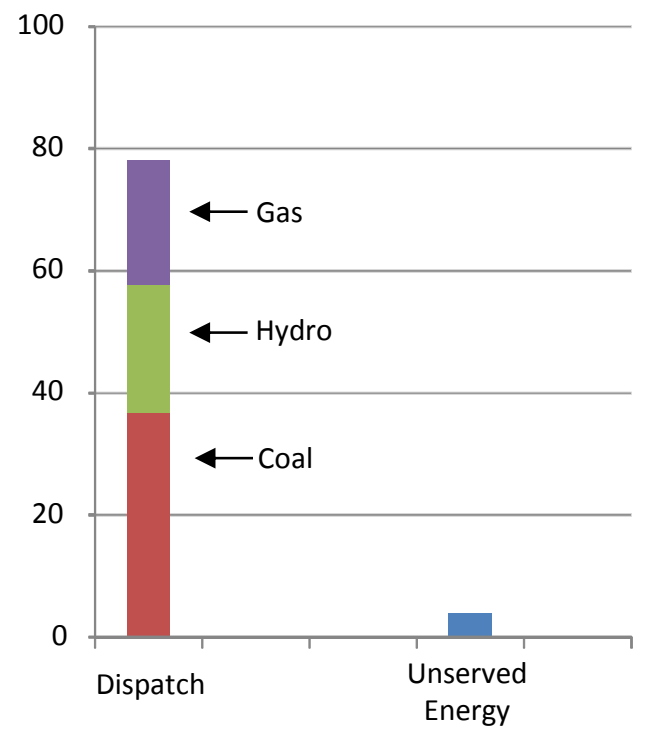

Figure 14: REAL Despatch by Country $(2010$ - 2014 total GWh 000)

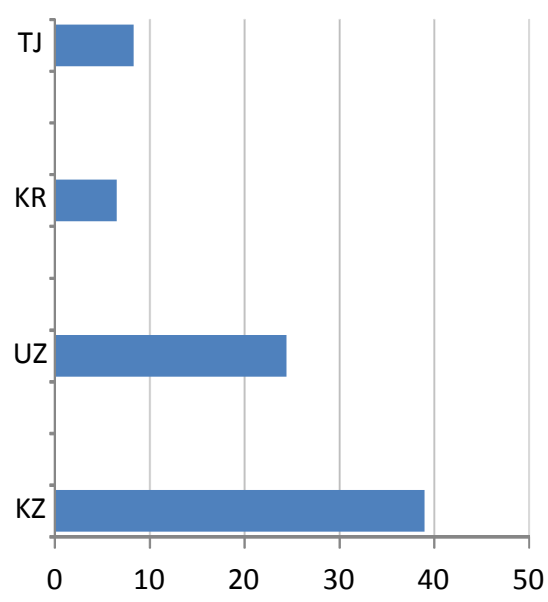

The overall system was dominated by coal (about $47 \%$ of production), followed by a roughly even split between hydro (not including water spills which amounted to about $6.5 \%$ of useful hydro production) and stations burning gas or oil. The estimated amount of unserved energy for the period was about $38,500 \mathrm{GWh}$, or approximately 5 percent of total consumption. The unserved energy (ENS) rate by country ranged from zero in Kazakhstan, to about 9-10\% of consumption in Tajikistan, Kyrgyzstan and Uzbekistan.

The system's cross border flows (as modelled) are shown in Figure 15 below.

Figure 15: Cross-Border Power Flows, REAL SIM C (2010 -- 2014 GWh)

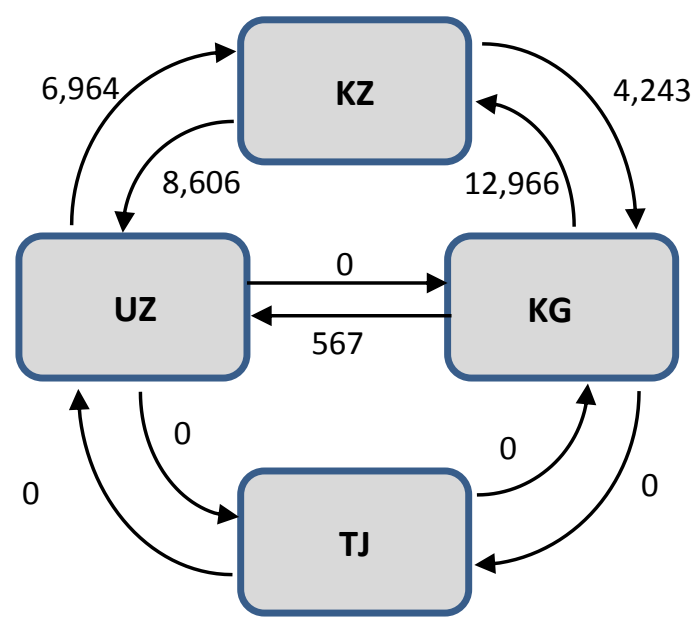




\subsection{The Efficient Trade Case: T100C}

The efficient trade case (T100C) uses the same level of fuel costs and demand (i.e., consumption plus energy-not-served) as in the Base Case (i.e., REAL SIM C), but removes the base-case constraints on individual station generation levels and actual transmission capacity usage.

Figures 16 and 17 below illustrate the system-wide dispatch results of the T100C case relative to the Base Case (which has also already been shown previously in Figures 13 and 14).

Figure 16: Aggregate Despatch and Unserved Energy (2010 - 2014 total GWh 000)

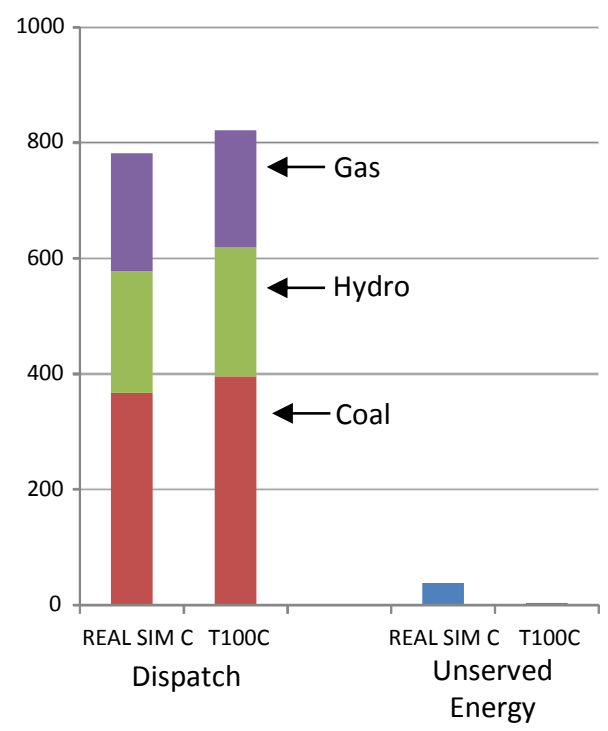

Figure 17: Despatch by Country (2010 - 2014 total GWh 000)

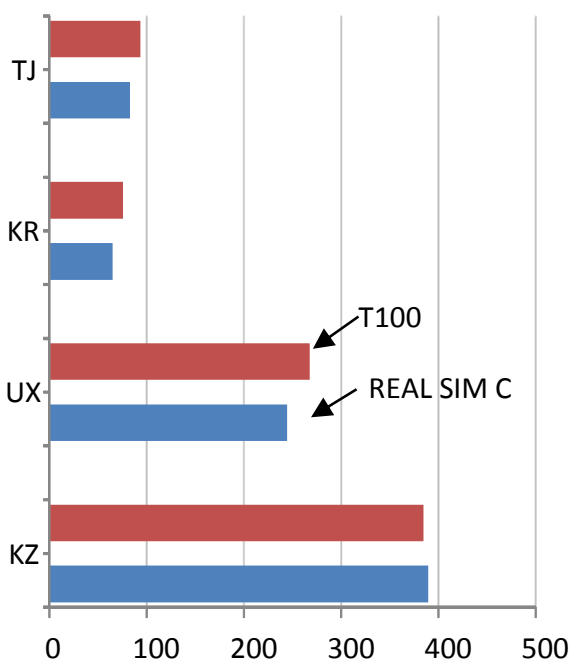

Several points are worth noting. First, in terms of aggregate dispatch, every country apart from Kazakhstan enjoyed an increase in output (Kazakhstan's decrease was only about 1\% of output). In terms of generation by fuel type, coal generation actually increased by the greatest amount (about $8 \%$ ) with hydro generation increasing by about 6\%, thus making nearly full use $(97 \%)$ of previously spilled water resources. Only gas / oil-fired generation decreased in aggregate (by about 1\%). The system's total energy-not-served was reduced by $90 \%$.

The total level of emissions for this scenario are 523.7 million tons of $\mathrm{CO} 2$ over the five year period, corresponding to an increase of approximately $4.7 \%$ compared to the Base Case described in section 3.1. This is due primarily to the overall increase in thermal generation (to meet unserved energy needs) in this scenario.

Figure 18 below illustrates the cross-border power flows in the T100C (Efficient Trade) case, with Figure 19 showing the incremental flows (i.e. increase or (decrease) in flows) of T100C relative to the Base Case (REAL SIM C). 
Figure 18: Cross-Border Power Flows, T100C (2010 -- 2014 GWh)

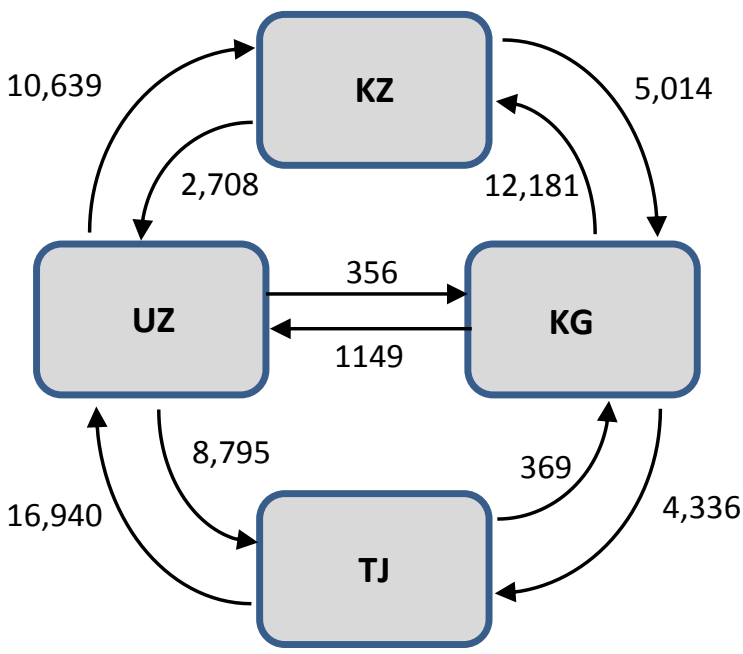

Figure 19: Increase /(Decrease) in Flows,



As can be seen from the Figures, flow over all inter-country links apart from two increased relative to the Base Case, in several cases substantially. We note that the modelling is done on a monthly basis, and so the effects of seasonality are shown in the flows, with all links operating in both directions at various times over the years modelled.

The incremental benefits (i.e., cost savings or other benefits) and incremental costs of the Efficient Trade case relative to the Base Case are shown in Figure 20 below.

Figure 20: Benefits of Efficient Trade (T100C) vs REAL SIM C (2010 - 2014 total USD Billions)

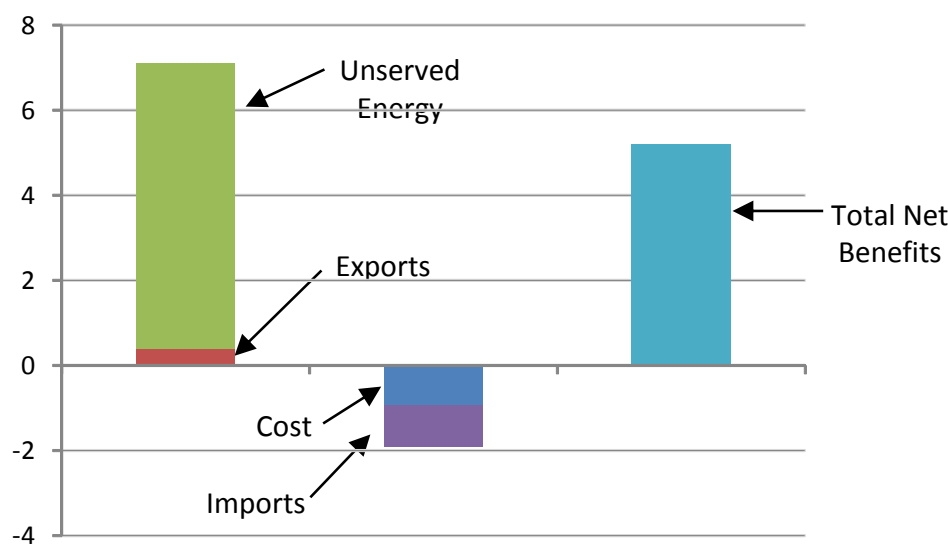

It is worth noting that in contrast to the analysis presented in Section 3, there is now a substantial benefit derived from meeting previously unserved energy. In this case, overall dispatch costs have actually increased relative to the base case, as both previously spilled hydro resources and thermal resources are used to meet this previously unserved demand. The aggregate net benefits to the system are approximately USD 5.2 billion. 


\subsection{Individual Country Benefits}

The analysis also allows the net benefits to be computed on a country-by-country basis. As noted previously, this requires a "price" to be estimated for cross-border power flows. This has been done by using the standard economic approach of setting the price at the marginal cost of production for unconstrained cross-border flows ${ }^{6}$. The sub-sections below summarize the resulting effects by country.

- Kazakhstan

Table 4 below shows the results for Kazakhstan.

Table4: Kazakhstan Benefits of Efficient Trade (T100C) vs REAL SIM C (2010 - 2014 total USD Millions)

\begin{tabular}{|l|c|c|c|}
\hline Category & $\begin{array}{c}\text { Incremental } \\
\text { Benefits }\end{array}$ & Incremental Costs & Total Net Benefits \\
\hline Dispatch Cost & 116 & -- & -- \\
\hline Unserved Energy & -- & -- & -- \\
\hline Imports & 927 & -- & -- \\
\hline Exports & -- & $(853)$ & -- \\
\hline Total & -- & -- & 190 \\
\hline
\end{tabular}

As the Table shows, Kazakh dispatch costs decreased relative to the Base Case, corresponding to the fact that Kazakhstan generates less energy in the Efficient Trade case. The country also shows incremental benefits in terms of imports, due to the reduction in calculated import prices. These benefits outweigh a decline in the total value of exports, leading to a net benefit of USD 190 million.

\section{- Uzbekistan}

Table 5 below shows the results for Uzbekistan.

Table 5: Uzbekistan Benefits of Efficient Trade (T100C) vs REAL (2010 - 2014 total USD Millions)

\begin{tabular}{|l|c|c|c|}
\hline Category & $\begin{array}{c}\text { Incremental } \\
\text { Benefits }\end{array}$ & Incremental Costs & Total Net Benefits \\
\hline Dispatch Cost & -- & $(615)$ & -- \\
\hline Unserved Energy & 4,529 & -- & -- \\
\hline Imports & -- & $(788)$ & -- \\
\hline Exports & 99 & -- & -- \\
\hline Total & & & 3,226 \\
\hline
\end{tabular}

\footnotetext{
${ }^{6}$ Where transmission constraints exist, so-called "congestion costs" are created which are split among the imports / exports. This effect was quite small in the modelling and does not have any effect on the overall general results or conclusions.
} 
Uzbekistan's principal benefits arise from avoiding significant unserved energy. This value was only partially offset by an increased cost of imports (as Uzbekistan imported hydropower from Tajikistan), resulting in total net benefits to Uzbekistan of about USD 3.2 billion for the five-year period.

- Kyrgyzstan

Table 6 below shows the results for Kyrgyzstan.

Table 6: Kyrgyzstan Benefits of Efficient Trade (T100C) vs REAL

(2010 - 2014 total USD Millions)

\begin{tabular}{|l|c|c|c|}
\hline Category & $\begin{array}{c}\text { Incremental } \\
\text { Benefits }\end{array}$ & Incremental Costs & Total Net Benefits \\
\hline Dispatch Cost & -- & $(396)$ & -- \\
\hline Unserved Energy & 986 & -- & -- \\
\hline Imports & 249 & -- & -- \\
\hline Exports & 61 & -- & -- \\
\hline Total & -- & -- & 900 \\
\hline
\end{tabular}

Kyrgyzstan's principal benefits arose due to the avoidance of unserved energy and a reduction in the cost of imports. Its dispatch costs increased through the increased use of coal. The net overall benefits to Kyrgyzstan amounted to USD 900 million over the five-year period $^{7}$.

- Tajikistan

Table 7 below shows the results for Tajikistan.

Table 7: Tajikistan Benefits of Efficient Trade (T100C) vs REAL (2010 - 2014 total USD Millions)

\begin{tabular}{|l|c|c|c|}
\hline Category & $\begin{array}{c}\text { Incremental } \\
\text { Benefits }\end{array}$ & Incremental Costs & Total Net Benefits \\
\hline Dispatch Cost & -- & $(27)$ & -- \\
\hline Unserved Energy & 1,188 & -- & -- \\
\hline Imports & -- & $(1,370)$ & -- \\
\hline Exports & 1,088 & -- & -- \\
\hline Total & -- & -- & 879 \\
\hline
\end{tabular}

Tajikistan's principal benefits came from the export of hydro power and the avoidance of domestic unserved energy. Import costs increased as a result of seasonal exchanges with

\footnotetext{
${ }^{7}$ As we also discuss in Section 4.2 below, Kyrgyzstan - and, indeed, the whole region - could benefit by sharing the provision of reserve capacity through the use of both Kyrgyz and Tajik hydro resources. The total potential regional benefits of avoided costs would amount to some USD 80 million / year which would be allocated by reserve capacity pricing among all the countries.
} 
Uzbekistan and Kyrgyzstan. The net benefits to the country totaled USD 879 million over the five-year period. ${ }^{8}$

\section{Results: Benefits from Fuel Savings, Meeting Unserved Demand from Efficient Trade at Market Fuel Prices and $\mathrm{CO}_{2}$ Costs (REAL SIM vs T100)}

In the previous cases set out in Sections 3 and 4, the power flows and energy dispatch costs were based on the actual costs of the fuels used for power generation in each individual country. These fuel costs were - in several cases - below what would be considered "export market" fuel prices.

Figure 21 below compares the variable operating costs of several illustrative power stations in the region, depending on whether they are assumed to produce with the fuel prices actually experienced (as the cases set out in Sections 3 and 4 above assume), or whether they are assumed to be operating with "export market" fuel prices together with an explicit cost for $\mathrm{CO}_{2}$ emissions.

Figure 21: Comparison of "Actual" and "Export"

Variable Costs for Illustrative Power Stations (USD /

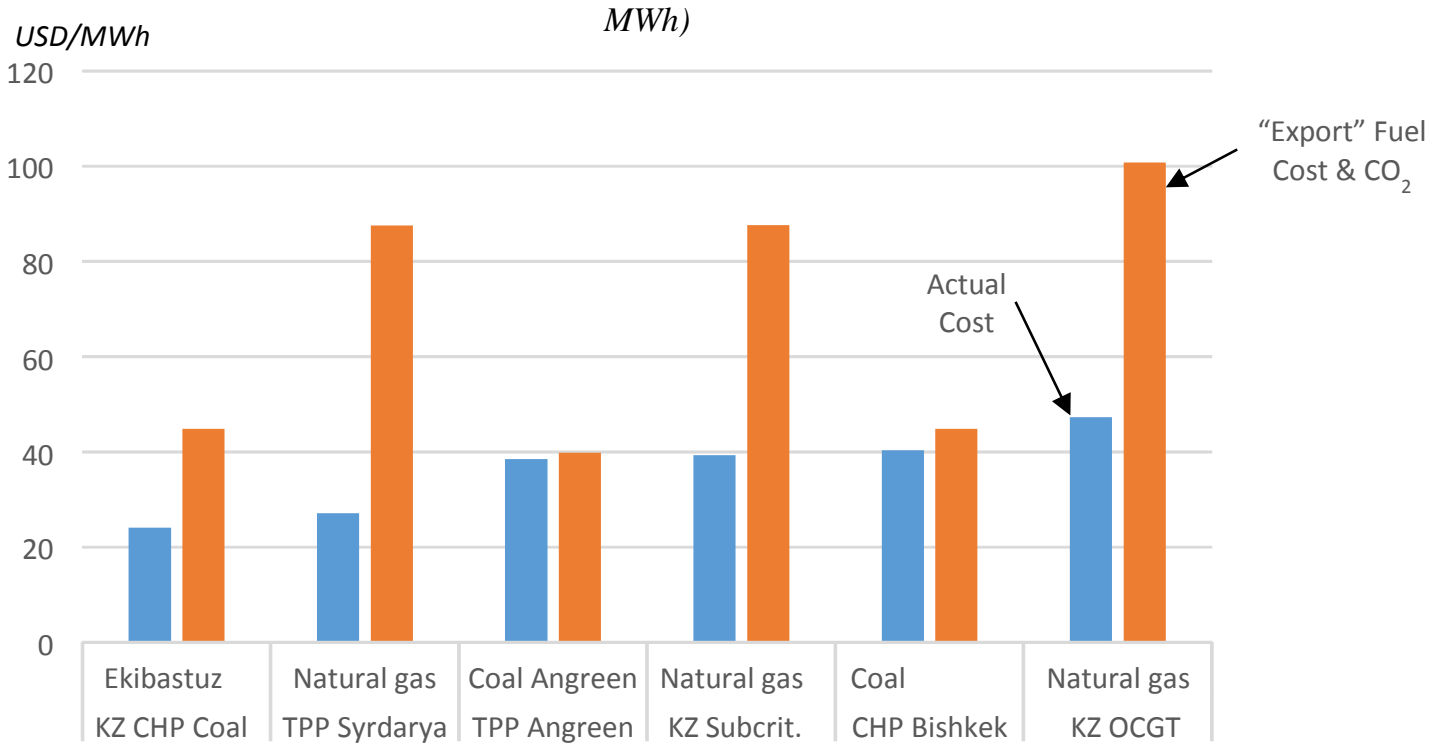

If the system were to be dispatched and power flows optimized on the basis of the higher variable costs (i.e., "export market" fuel prices etc.), we would expect the net benefits of efficient trade (including benefits of serving previously unserved energy) to be larger as there would be greater scope for low-cost thermal generation (e.g., Kazakh coal) to displace higher cost generation (e.g., Uzbek gas / oil) in addition to the value of using hydro generation to replace the highest cost thermal generation first.

Figure 22 below illustrates this. The "T100" case was developed using "export market" fuel prices (with carbon charges) to determine the value of dispatch savings (i.e., economic resource costs) which would be achieved under this scenario. It is compared to the "REAL

\footnotetext{
${ }^{8}$ As noted in footnote 6 above, Tajikistan could also share the provision of regional capacity reserves with Kyrgyzstan, thus increasing the economic value benefits to Tajikistan.
} 
SIM" case which is analogous to the REAL SIM C case with the exception that it too is based on "export market" fuel prices (with carbon charges) to provide the baseline for calculation of the changes in dispatch costs and the value for cross-border flows.

Figure 22: Benefits of Efficient Trade and Export Fuel Prices (T100) vs REAL SIM (2010 - 2014 total USD Billions)

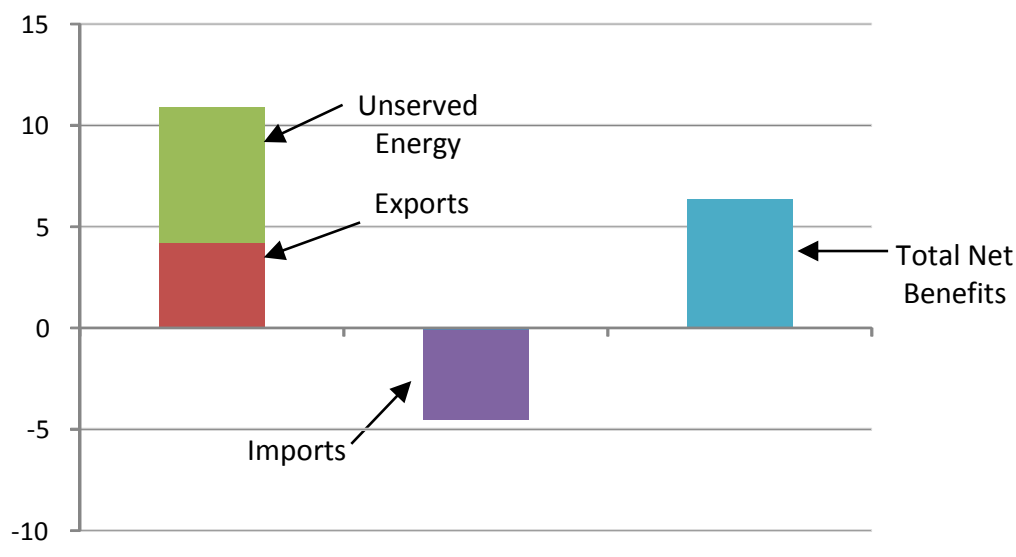

In this case, the value of reduced unserved energy is the same as in the principal Efficient Trade case, but the system dispatch cost savings has grown substantially, reflecting the benefits of saved resources priced at "export price" values. Both exports and imports values have grown with the net difference between them representing mostly transmission losses (now more costly as they are based on "export market" fuel prices) as previously. The overall net benefits to the aggregate system have grown from USD 5.2 billion in the analysis set out in Section 4 to about USD 6.4 billion here over the five-year period.

\section{Ancillary Services}

It is possible that a more unified CAPS system would also be able to make savings in terms of operating reserves. If each country were to provide its own reserves individually ${ }^{9}$, it is estimated that a total of $1900 \mathrm{MW}$ of reserves would be required. In contrast, if reserves were shared among the four countries, the total requirement would drop to an estimated 800 MW.

Figure 23 below shows the cost of different scenarios for providing reserves. The left-hand bar shows the estimated cost of the provision of 1900 MW of reserves (i.e., individual country provision). If the countries were to share reserves, only some $800 \mathrm{MW}$ of reserves would be required. The right-hand bars show this shared provision, first as if they were purchased at regional market prices, and second at the cost of provision using Kyrgyz and Tajik hydro resources.

\footnotetext{
${ }^{9}$ We recognise that in fact today some reserves are purchased from the Russian power system; the costs and MW extent of this are not addressed here
} 
Figure 23: Cost of Providing Reserves

(5-Year Period, total USD Millions)

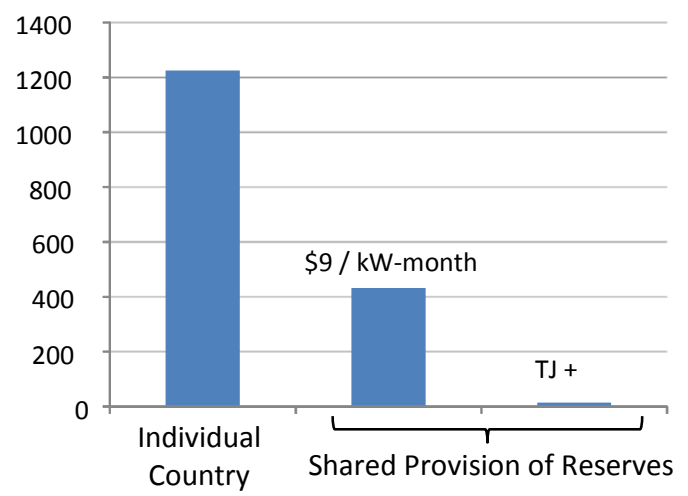

It is clear that the least-cost option would be for the region to use Tajikistan's and Kyrgyzstan's hydro resources, which it is estimated could be harnessed without disruption to those countries' generation plans. The resulting savings for the region - of over USD 400 million over a five-year period relative to purchasing reserves at regional market prices could be shared among the countries for the benefit of each, with Kazakhstan and Uzbekistan making payments below the Russian market rate to the hydro generators that would provide the reserves and enjoy the resulting revenues.

Thus, all countries in the region can benefit from pooling reserves. The benefits come in two forms: first, from the reduction in the overall total quantity of reserves needed, and second from the potential sharing of the least-cost source of providing reserves, the large hydroelectric stations in the Kyrgyz and Tajik Republics. This latter choice would not only bring considerable cost savings to all, but would effectively result in the whole regional system operating once again in the manner in which it was originally designed.

\section{Overall Conclusions}

\section{The Current Situation is Costly for All Countries}

The shortcomings of today's mode of operations are obvious to all. First, the regional system is not operating as planned and as it was organized with the development of the regional high voltage network. Summer surpluses in the hydro countries are not being exchanged efficiently with thermal generation in other countries in a manner to meet overall demand and summer water release requirements. Today's operational mode results in substantial waste of hydro resources (through water spills) while at the same time consumer demand goes unfulfilled. Overall system operations are excessively costly and countries have reduced potential for exports of both electricity and fuel.

\section{Efficient Trade Brings Significant Benefits to the Region}

As the principal analysis shows, efficient trade brings substantial benefits to the region. The monetary value of the aggregate benefits from the main comparison (i.e., the "REAL SIM C" case compared to "T100C") comes to USD 5.2 billion over the historic five-year period. This value could have been shared via economic pricing of trade, with Uzbekistan enjoying some USD 3.2 billion in benefits and Kazakhstan having USD 190 million. Tajikistan (USD 879 million) and Kyrgyzstan (USD 900 Million) would each enjoy benefits in between this range. These values - the overall total and the corresponding benefits to each country - have already been lost to the region. 
The region has been able to withstand this loss of value because (again, as the analysis has shown) much of the loss is due to not providing service to meet consumers' aggregate demand. While curtailing consumers does not result in an immediate cash cost, it does hinder economic growth and eventually (if not already) cause consumers - both businesses and individuals - to become displeased with their energy suppliers, and, eventually, their governments. However, even if only the cash value of benefits is counted, the analysis of REAL SIM C ENS / T100C ENS illustrated that the cash-only benefits of efficient trade still came to approximately USD 1.5 billion.

\section{It is Possible That All Countries in the Region will Benefit from Efficient Trade}

The total benefits of efficient trade are "allocated" among trading partners by trading prices. We expect that prices in any future market will be determined by the rules and organization of those markets. Nevertheless, this analysis has shown that a relatively simple pricing can result in each individual country being a "winner" from increased trade. Some countries will benefit from saving high cost fossil fuels in favor of imported hydro; others will benefit from greater ability to meet domestic demand; others will benefit from either exporting low-cost thermal generation or even saved fossil fuels. The various allocations of the total value are noted in point 2 above.

\section{The Estimates of Trade Benefits are Robust to Different Scenarios}

We have tested the results with varying approaches. In addition to the principal efficient trade case, we have also developed a case (T100) which values traded electricity and also potentially exported saved fuels at "export" prices. We have also examined trade in cases where cross-border transmission capacities were constrained to less than full availability. In all cases, benefits can be enjoyed through efficient trade.

\section{The Future may be Uncertain, but Trade Benefits can be Achieved Now}

Certainly there are projects in the region focused on opportunities other than intra-regional trade; large-scale transmission projects such as CASA or TUTAP are examples. If these, or other, projects are realized, they will bring new markets to the energy producers of the region. However, the realization of these projects is in the future, whereas the benefits of efficient regional trade are here today, waiting only to be grasped.

\section{8. $\quad$ Next Steps}

There are many practical steps necessary to take in order to implement efficient trade. However, a suitable plan could be developed which could bring substantial benefits of trade relatively quickly (possibly through simplified trading systems), with greater sophistication and technical capabilities developed over time.

Many of the detailed steps are described in the AF Mercados Report. Key among them are:

1. Near-Term Steps, including:

a. Develop inter-governmental and stakeholder agreement on the potential benefits and the nature and objectives of the systems to be adopted 
b. Define the type of transactions or market to be developed (e.g., bilateral contracts; spot markets, etc.) and well as principles for a fair methodology for settlements and compensation of schedule deviations

c. Identify the role of central trading and dispatch institutions (such as CDC Energia)

d. Improve regional control systems, communications, and acquire appropriate software

e. Identify and adopt necessary pan-regional technical and commercial documents (e.g., grid codes, metering codes, settlement rules)

f. Define a scheme for mutual support during emergency operations

2. Medium-Term Steps, including:

a. Improve system supervision and control software

b. Improve commercial metering

c. Adopt a system for coordinated system planning, especially insofar as high voltage grid development is concerned

3. Longer-Term Steps, including:

a. Implement necessary technological changes and improvements

b. Move forward with regional grid development and power system projects 